\title{
The Use of Materials from Biomass as Construction Materials
}

\author{
Francesca Giglio \\ Department of Architecture and Territory, University of Mediterrean Studies, Reggio, Italy \\ Email: francessca.giglio@unirc.it
}

Received April 24, 2013; revised May 26, 2013; accepted June 4, 2013

Copyright (C) 2013 Francesca Giglio. This is an open access article distributed under the Creative Commons Attribution License, which permits unrestricted use, distribution, and reproduction in any medium, provided the original work is properly cited.

\begin{abstract}
The paper describes some studies conducted by the author, about low impact materials and, particularly, on alternative uses of biomass materials for building materials. Italy needs to develop renewable energy sources and agriculture offers many opportunities: biomass, vegetable residues for livestock breeding, food industry waste, organic waste, solid biofuels, biogas, and biofuels, will be the new renewable energy sources. Researches for promoting sustainable development, including chemistry field are increasing interest in the exploitation of vegetal biomass, in particular waste as a raw material for production of bio-products and biofuels. Not always, however, the use of waste materials such as biomass is the most appropriate, or in any case, the one with less energy expenditure. As ever more evident, in fact, the construction sector is approaching the possibility of using these materials for other purposes, combining the demands of saving natural resources, the need for energy efficiency in buildings and production processes.
\end{abstract}

Keywords: Eco-Innovation; Biomass and Construction; Hemp’s Masonry

\section{Introduction}

The document is divided into three phases: the first phase describes the scientific scope of reference compared to the construction sector, materials and innovation with results, describing the new frontiers of construction, oriented towards eco-innovation, as required by the latest European funding. The second part of the document is related to the state of the art of some experiments conducted in Italy, referring to alternative uses of materials from biomass, with particular reference to the use of natural fibers in construction. In addition, studies carried out are described in the offer of the productive sector to the sustainable demand relative to key technical elements of the building. The third part of the document describes the new services-information tools for the project, highlighting the importance of materials libraries in Europe, as an instrument of knowledge and dissemination of innovative technology of new materials on the market. The aim of the document is, therefore, an advancement of knowledge in the field of testing of materials based on natural for innovative uses in the field of construction.

\section{New Constructive Frontiers to Eco-Innovation}

European strategies oriented towards eco-efficient inno- vation in the building sector are increasingly oriented towards materic innovation and energy efficiency, with greater decision-making role to businesses, in a logic of "innovation chain", with the aim of experiment new proposals materic-constructive of an environmental nature $[1,2]$. Italy needs to develop renewable energy sources and agriculture offers many opportunities: biomass, vegetable residues livestock breeding, food industry waste, organic waste. Solid biofuels, biogas, biofuels, will be the new renewable energy sources. In researches for promoting sustainable development, including in chemistry field is increasing interest in the exploitation of vegetal biomass, in particular waste as a raw material for production of bio-products and bio-fuels [3]. The commitment to use renewable resources to an increasing extent, by the material and energy profile, and give rise to new challenges both in the use of biomass in research and policy areas. Hence, therefore, the need to promote all actions that might facilitate activation of the supply chain from available biomass, but also economic ecological sustainability of such action.

The activation of a bioenergy chain necessarily implies the initiation and coordination of a complex set of relations on the territory. This characteristic makes the biomass sector in need of support, coordination and promo- 
tion, considering that it is the more complex mechanism among the renewable sources [4]. Not always, however, the use of waste materials such as biomass is the most appropriate, or in any case, the one with less energy expenditure. Us ever more evident, in fact, the construction sector is approaching the possibility of using these materials for other purposes, combining the demands of saving natural resources, the need for energy efficiency in buildings and production processes.

\section{Biomass and Construction Materials}

The experimental use of new building materials, is the use of certain raw energy from biomass such as firewood, agricultural residues and forestry waste from the food industry, a new area to investigate. The pruning of olive groves, vineyards and orchards produce a large amount of wood waste is not always valued properly. Similarly, the problem of the management of by-products resulting from the extraction of olive oil and the reduction of their impact on the environment has been the subject of many scientific studies aimed at identifying possible solutions aimed at disposal painless or better yet their recycling, finalized to the realization of building materials.

In such sense, the agriculture and forestry industry can become a major player in the energy sector, as everything it's get, and as waste (prunings, non-marketable products, waste from forest harvesting, etc.) and as a finished product (sorghum, corn, poplar, etc.), is composed of carbon and is therefore potentially be used to produce energy. Scientific studies and experimentations in the research lab, in this context, is focused on innovation in the composition of matter of concrete, plaster, insulation materials, etc. [5,6]. In particular, in addition to recycling of waste material, the significant amount of ash in Italy arising from biomass energy plants, is directing research, supported by the current legislation on the recovery of ash in cement and in brick industry. In addition to these experiments, the attention of the studies presented in the paper is directed to the use of natural fibers in hybrid materials, in particular, the use of hemp in construction elements for masonry.

\section{Materic Alternative to Masonry: Hem Biocomposite}

Hemp is a plant that produces more biomass in the world, growing in 4 months up to $4 \mathrm{~m} / \mathrm{h}$, for this reason is called “carbon negative material”. Until a few decades ago, Italy was the second largest producer of hemp and it was firmly rooted in the tradition of production. Because of the inability to compete with the Asian markets, the use of hemp has been increasingly reduced. Currently, thanks to the incentives of EU funding, is starting up again for the reintroduction of hemp fiber and the formation of chains of products.

In Europe, the use hemp is quite generalized and extended to other areas, such as Germany, which uses the hemp fibers for the automotive industry, through fibroresine, plastic and padding, now used by all the major manufacturers, France, which using fiber-reinforced mortar,) plaster with untreated hemp and lime, made of hemp-lime and water with a grainy texture similar to cork and Italy, where hemp is widespread in the textile and construction sectors through the use of the flower and drum for wax, paint, insulation boards, plaster and precast blocks $[7,8]$.

The composite obtained with the use of hemp fiber, is currently commercially in the form of blocks, or for entire construction systems in blocks of hemp (and lime) and wood structure. The biocomposite used is usually formed from the woody part of the stem of hemp with a binder based on lime. Once cured, the biocomposite becomes rigid and lightweight with wide range of applications. Combining blocks of hemp and lime to lime mortar fiber-reinforced, developed in France, it would get the first technology completely based on hemp (technical lime-shives). The advantages of this technology are:

- Construction of energy efficient buildings, biocompatible, with zero emissions.

- $\mathrm{CO}_{2}$ absorption during the production and use of material (combating climate change).

- Thermal and acoustic insulation and vapor permeability.

- Finding materials on site, local supply chain, lower costs of construction.

\section{Materic Innovation and Information Tools}

Product innovation, must necessarily be accompanied by an innovation in the dissemination of information of the product itself, to encourage and support the use of materials and innovative construction techniques.

The use of new materials for the project never before used and never tested involves more and more necessity of information tools for the project collecting all the technical and environmental information available for these materials, to encourage the use and dissemination between designers and clients. In particular, the use of construction materials, innovative, for material composition or performances, needs to be accompanied by a series of specialized information of a technical/environmental describing the product's innovative features in terms of saving resources and energy efficiency, during production and use, in addition to the characters of the recyclability of the product.

Among the new information tools for the project, there are materials libraries, physical and virtual places for innovation diffusion material, which, through informa- 
tion databases of experimental materials and production samples exposed to the true innovative materials, both for the construction sector and in other research areas. In addition to the database, the materials libraries provide materic archives through which to verify personally the technical and sensory materials. In Europe, what's evident is the increasing spread of materials libraries, as an instrument of knowledge and dissemination of innovative technology of new materials on the market, both organized by university institutions, which scientific research institutions allow materials such as those described in the document, to have a greater expansion in the area by the insiders.

\section{Conclusions}

Among the new construction scenarios for the project, the use of materials with low energy consumption and high efficiency, from chains or local waste materials is certainly one of the aspects of major scientific interest and investigation. Being a field still very much open, it will need to make it more accessible and manageable, having a strict management of information relating to these products. In particular, the need to manage technical-environmental information, will be related to:

- life cycle of the product: energy consumption and environmental impact (pre-consumption phase)

- compatibility of the product in solution and in the context (use-management phase)

- product's end-of-life scenario: reuse, recycling, landfill (post-consumer phase).

In particular, for new construction materials from biomass, the field of research is still very open and to be addressed under different points of view:

- physical and mechanical properties

- health

- energy performances
- durability

- morphological and tactile appearance

- production costs

and many other aspects to be assessed on the basis of specific uses. A strong synergy between science and production sector, will contribute to the research advancement in this field, through experiments with local character and specific performance targets for different needs.

\section{REFERENCES}

[1] S. Sala and V. Castellani, “Atlante Dell'Ecoinnovazione,” Franco Angeli, Milano, 2011.

[2] G. Ferraris, "Distretti. Culture Locali e Vantaggio Competitivo,” Baldini\&Castoldi, Milan, 2012.

[3] G. S. Mugnozza, G. Cascone and P. Tassinari, "Stato Dell'Arte e Prospettive Della Ricerca nel Settore Delle Costruzioni Rurali e Territorio Agroforestale,” Conference of Medium Term of Italian Association of Agricultural Engineering, Belgirate, 22-24 September 2011.

[4] M. Reho, "Fonti Energetiche Rinnovabile, Ambiente e Paesaggio Rurale,” Franco Angeli, 2009.

[5] S. Maglia and M. Labarile, "New on Recycling and Biomass in the Regulatory Landscape Community," Ambiente e Sviluppo, 2011.

[6] C. Ricerca, “Roadmap Della Ricerca e Dell’Innovazione in Materia di Fonti Energetiche Rinnovabili Emergenti in Italia,” 2009, Report No. 08005964.

[7] C. Vasile and G. Zaikov, "Environmentally Degradable Materials Based on Multicomponent Polymeric Systems,” Koninklijke Brill NV, Leiden, 2009.

[8] J. Mussig, "Industrial Applications of Natural Fibres: Structure, Properties and Technical Applications,” John Wiley \& Sons, Hoboken, 2010. doi:10.1002/9780470660324 